\title{
Optogenetic Activation of Dorsal Raphe Serotonin Neurons Rapidly Inhibits Spontaneous But Not Odor-Evoked Activity in Olfactory Cortex
}

\author{
Eran Lottem, ${ }^{1 *} \oplus^{\oplus}$ Magor L. Lörincz, ${ }^{1,2,3 *}$ and Zachary F. Mainen ${ }^{1}$ \\ ${ }^{1}$ Champalimaud Neuroscience Programme, Champalimaud Centre for the Unknown, 1400-038, Lisbon, Portugal, ${ }^{2}$ Research Group for Cellular and Network \\ Neurophysiology of the Hungarian Academy of Sciences, Department of Physiology, Anatomy, and Neuroscience, and ${ }^{3}$ Research Group for Cortical \\ Microcircuits of the Hungarian Academy of Sciences, Department of Physiology, Anatomy and Neuroscience, University of Szeged, 6726, Szeged, Hungary
}

Serotonin (5-hydroxytriptamine; 5-HT) is implicated in a variety of brain functions including not only the regulation of mood and control of behavior but also the modulation of perception. 5-HT neurons in the dorsal raphe nucleus (DRN) often fire locked to sensory stimuli, but little is known about how 5-HT affects sensory processing, especially on this timescale. Here, we used an optogenetic approach to study the effect of 5-HT on single-unit activity in the mouse primary olfactory (anterior piriform) cortex. We show that activation of DRN 5-HT neurons rapidly inhibits the spontaneous firing of olfactory cortical neurons, acting in a divisive manner, but entirely spares sensory-driven firing. These results identify a new role for serotonergic modulation in dynamically regulating the balance between different sources of neural activity in sensory systems, suggesting a possible role for 5-HT in perceptual inference.

Key words: feed-forward; feedback; inhibition; neuromodulation; odor

\section{Significance Statement}

Serotonin is implicated in a wide variety of (pato)physiological functions including perception, but its precise role has remained elusive. Here, using optogenetic tools in vivo, we show that serotonergic neuromodulation prominently inhibits the spontaneous electrical activity of neurons in the primary olfactory cortex on a rapid $(<1 \mathrm{~s})$ timescale but leaves sensory responses unaffected. These results identify a new role for serotonergic modulation in rapidly changing the balance between different sources of neural activity in sensory systems.

\section{Introduction}

Serotonin (5-hydroxytriptamine; 5-HT), released from neurons located in the brainstem dorsal raphe nucleus (DRN), is involved in the regulation of mood and in behavioral control in relation-

Received Aug. 10, 2015; revised Sept. 21, 2015; accepted 0ct. 10, 2015.

Author contributions: E.L., M.L.L., and Z.F.M. designed research; E.L. and M.L.L. performed research; E.L., M.L.L., and Z.F.M. analyzed data; E.L., M.L.L., and Z.F.M. wrote the paper.

This work was supported by European Research Council Advanced Investigator Grant 250334 (Z.F.M.), the Champalimaud Foundation (Z.F.M.), Hungarian Scientific Research Fund Grant NF 105083 (M.L.L.), Hungarian Brain Research Program Grant KTIA_NAP_13-2-2014-0014 (M.L.L.), and the Human Frontier Science Program (Z.F.M.) and Fellowships LT001009/2010L (M.L.L.) and LT000881/2011L (E.L.). We thank Drs. C. Poo, B. Atallah, and M. Murakami for helpful discussions.

The authors declare no competing financial interests.

*E.L. and M.L.L. contributed equally to this work.

Correspondence should be addressed to either of the following: Magor L. Lörincz, Research Group for Cellular and Network Neurophysiology of the Hungarian Academy of Sciences, Department of Physiology, Anatomy, and Neuroscience, University of Szeged, Közép fasor 52, 6726, Szeged, Hungary, E-mail: mlorincz@bio.u-szeged.hu; Zachary F. Mainen, Champalimaud Neuroscience Programme, Champalimaud Centre for the Unknown, 1400-038, Lisbon, Portugal; E-mail: zmainen@neuro.fchampalimaud.org.

DOI:10.1523/JNEUROSCI.3008-15.2016

Copyright $\odot 2016$ the authors $\quad 0270-6474 / 16 / 360007-12 \$ 15.00 / 0$ ship to rewards and punishments (Soubrie, 1986; Cools et al., 2008; Dayan and Huys, 2009). Although less studied, it is also implicated in the regulation of sensory function (Davis et al., 1980; Jacobs and Azmitia, 1992; Deemyad et al., 2013). Although these effects have been characterized chiefly on a relatively slow timescale, elicited pharmacologically or by electrical stimulation, optogenetic stimulation of DRN 5-HT neurons can reduce behavioral sensitivity to noxious mechanical stimuli on the timescale of seconds (Dugué et al., 2014), and similar protocols can exert other effects on behavior within $<1$ s (Fonseca et al., 2015). Moreover, the firing of DRN 5-HT neurons is modulated on the subsecond timescale (Waterhouse et al., 2004; Ranade and Mainen, 2009; Cohen et al., 2015). Together, these data suggest that transient changes in DRN activity could be coupled to similarly rapid influences on sensory processing.

Here, we investigated the effect of 5-HT on olfactory sensory processing. In the olfactory bulb (OB), 5-HT can affect odor processing by inhibiting glutamate release from the terminals of olfactory receptor neurons (Petzold et al., 2009) and exciting external tufted cells (Liu et al., 2012). The primary olfactory cor- 
tex or anterior piriform cortex (aPC) is also a significant target of DRN innervation (De Olmos and Heimer, 1980; Datiche et al., 1995). Principal neurons in aPC receive two major sources of input: (1) feedforward input from the OB via the lateral olfactory tract (LOT); and (2) feedback input comprising the recurrent collaterals of local principal neurons and top-down innervation from other brain regions (Haberly, 1998; Isaacson, 2010). It has been proposed that recurrent olfactory cortex feedback circuitry implements associative memory functions such as pattern completion and generalization (Haberly, 1985, 2001). The neuromodulators acetylcholine and noradrenaline have been shown to differentially inhibit feedback circuits (Hasselmo and Bower, 1992; Hasselmo et al., 1997), a function theorized to regulate associative memory function (Hasselmo and Bower, 1992; Hasselmo et al., 1997). However, these results are based on in vitro recordings, and their consequences on in vivo firing in the olfactory system have not been investigated.

In Bayesian theories of perception, experience is used to build predictive models of the world that generate expectations or priors (Kersten et al., 2004; Knill and Pouget, 2004). In the process of perceptual inference, priors carried by feedback inputs are combined with sensory data (likelihoods) carried by feedforward inputs to infer a posterior (Rao and Ballard, 1999; Friston, 2010; Summerfield and de Lange, 2014). It has been proposed that spontaneous activity, in the absence of sensory input, will reflect model-based priors (Fiser et al., 2010; Berkes et al., 2011).

In this work, we combine electrophysiological and optogenetic tools to study the effects of DRN 5-HT on the aPC in vivo. We show that 5-HT rapidly suppresses the spontaneous firing of aPC neurons but spares odor-driven firing. Our results identify a novel role for serotonergic modulation in dynamically regulating the balance between different sources of neural activity in sensory systems acting on a rapid timescale. Interpreted in the context of predictive coding, these observations suggest that $5-\mathrm{HT}$ regulates the influence of priors on perceptual inference.

\section{Materials and Methods}

All procedures were performed in accordance with the European Union Directive (86/609/EEC) and approved by Veterinary DirectorateGeneral of Portugal. Adult C57BL/6 mice were used in all experiments. All efforts were made to minimize the suffering and number of animals used in each experiment. The SERT-Cre mouse line (Zhuang et al., 2005) was used to express channelrhodopsin-2 (ChR2) selectively in serotonergic cells. Optogenetic methods followed methods described previously (Dugué et al., 2014). Data are presented as mean \pm SEM, unless stated otherwise.

Viral infections. Male mice heterozygous for Cre recombinase under the control of the serotonin transporter (Sert) gene [Slc6a4tm1(cre)Xz; Zhuang et al., 2005] were injected with $0.5-1 \mu \mathrm{l}$ of AAV2/1-Flex-ChR2YFP in the DRN [coordinates: anteroposterior (AP), $-4.7 \mathrm{~mm}$; dorsoventral (DV), 3.1-3.6 mm]. Histology confirmed prominent and specific ChR2 expression in DRN 5-HT neurons (Dugué et al., 2014).

Surgical procedures and in vivo electrophysiology. Adult mice (postnatal day 60-120) infected previously (2-5 weeks) with ChR2 in DRN 5-HT neurons were anesthetized with urethane $(1.4 \mathrm{~g} / \mathrm{kg})$. Body temperature was maintained at constant levels using a heating plate (Supertech). After exposing the skull, a small hole was drilled above target areas at stereotaxic coordinates [aPC: AP, $+2.3 \mathrm{~mm}$; lateral, $2.5 \mathrm{~mm}$; DV , 2.9-3.6 mm]. The dura mater was then punctured, and the electrodes were lowered into the brain. A stainless steel screw ( $0.8 \mathrm{~mm}$ diameter) was placed into the skull over the cerebellum and served as a ground/reference.

Next, an optrode consisting of an optical fiber (200 $\mu \mathrm{m}$ diameter; numerical aperture 0.38 ) coupled to a $470 \mathrm{~nm}$ laser (Laserglow Technologies) and a microelectrode was lowered into the DRN (coordinates: $\mathrm{AP},-4.7 \mathrm{~mm}$; DV , $3.0-3.6 \mathrm{~mm}$ ) at a $32^{\circ}$ angle. The electrode was low- ered while brief light pulses were delivered $(10 \mathrm{~ms}, 0.5 \mathrm{~Hz})$ until a prominent optical local field potential was observed on the optrode located in the DRN indicative of synchronous firing in ChR2-expressing 5-HT neurons (Dugué et al., 2014).

Extracellular single units were recorded using metal microelectrodes (1-3 M $\Omega$; FHC), 16-channel silicon probes (NeuroNexus Technologies), or glass pipettes filled with $0.5 \mathrm{M} \mathrm{NaCl}$ (resistance, $10-25 \mathrm{M} \Omega$ ). Recordings were acquired digitally using Spike2 software (Cambridge Electronic Design). Data were stored on a personal computer for offline analysis. Spike sorting was performed with Spike2 software (Cambridge Electronic Design).

Odor presentation and optogenetic stimulation of the DRN. While under anesthesia, mice were presented with one or several different odors $[S(+)$-2-octanol, $R$-(-)-2-octanol, amyl acetate, (-)- $\alpha$-pinene, (+)- $\alpha$ pinene, $(S)-(-)$-pulegone, and diallyl sulfide diluted in mineral oil in a 1:10 ratio] using a custom-built olfactometer. Diluted liquid odors and a blank control odor (pure mineral oil) were loaded onto disposable syringe filters ( $20 \mu \mathrm{l}$; Whatman) that were then inserted into a manifold. The flow of air through each of the filters was controlled independently using a three-way solenoid valve (NResearch). At any given moment, only one of the valves was open, passing either odorized or blank air streams at a flow rate of $100 \mathrm{ml} / \mathrm{min}$ through the filter and into the manifold. This stream was mixed within the manifold with a second, "carrier" stream of clean air (flowing at $900 \mathrm{ml} / \mathrm{min}$; both streams controlled using mass flow controllers; Aalborg) from which it was delivered though Teflon tubes to the animal's nose. Each recording session consisted of 5-20 blocks. Each block contained all the different trial combinations of odor and photostimulation. Odors were presented for either 1 or $2 \mathrm{~s}$ ( $n=5$ and 58 neurons, respectively) and photostimulation ( $10 \mathrm{~ms}$ pulse width, $1-30 \mathrm{~Hz}$ ) started $1 \mathrm{~s}$ before odor stimulation and coterminated with it. A 20-30 s interval was inserted between trials to allow for activity to return to baseline. In some experiments, we used a range of stimulation frequencies $(1,5,10$, and $30 \mathrm{~Hz} ; n=15)$, whereas in others, different stimulus durations were used $(2.1,3$, and $7 \mathrm{~s} ; n=5)$.

Histology. At the end of some experiments, animals were given an overdose of urethane and perfused through the heart with $20 \mathrm{ml}$ of saline, followed by $50 \mathrm{ml}$ of ice-cold $4 \%$ paraformaldehyde in PBS, and their brains removed and sectioned after overnight fixation for histology.

Data analyses. To test for significant modulations of firing rates attributable to either odor or photostimulation, we used receiver operating characteristic (ROC) analysis. We first generated two firing rate probability distributions, one for the control condition and the other for the test. For photostimulation modulation analysis, we calculated the firing rates in a $4 \mathrm{~s}$ window aligned on stimulus onset. In cases in which multiple stimulation frequencies were used, the highest frequency of stimulation was chosen; $3 \mathrm{~s}$ stimulation was chosen in case of different stimulation durations. For odor modulation analysis, the window had the same duration as the odor stimuli ( 1 or $2 \mathrm{~s}$ ). We then calculated the area under the ROC curve (AUC) comparing the two distributions. Finally, we generated 1000 shuffled distributions, in which individual trials were assigned to either distribution randomly and calculated the AUC values for these shuffled data, as well. Conditions in which the real AUC value was $>97.5 \%$ or $<2.5 \%$ of the shuffled values were considered significant.

The value obtained using this analysis was also used to assign a modulation index (MI), which was calculated as follows: $\mathrm{MI}=2 \times$ (AUC - 0.5). An MI value of 1 corresponds to the strongest possible excitation (in which the lowest value of the modulated distribution is higher than the highest value of the control distribution), and a value of -1 corresponds to the strongest possible inhibition.

To calculate the latency to inhibition onset, we used change point analysis (Basseville and Nikiforov, 1993). For each unit, we calculated the cumulative sum of the difference between the (unsmoothed) peristimulus time histogram (PSTH) and mean firing rate throughout the trial. For inhibited units, these curves are characterized by an initial rising slope (in which the mean firing rate is higher than average) that peaks and starts decreasing at the onset of inhibition. The maximum of this curve within a $4 \mathrm{~s}$ time window aligned with photostimula- 
tion onset was taken to be the change point, and its delay from stimulation onset was the latency.

For inhibited units that were stimulated with different frequencies, we calculated the dose response by first dividing each average firing rate by its corresponding control. In the case of different photostimulation durations, we calculated firing rates during a $7 \mathrm{~s}$ time window aligned to stimulation onset (the duration of the longest condition) and normalized these values to the control.

To test whether inhibition scaled with baseline firing rate across the population of recorded neurons and to test whether such scaling was divisive and/or subtractive, we calculated average firing rates during pre-photostimulation (4 to $0 \mathrm{~s}$ before onset) and post-photostimulation (0 to $4 \mathrm{~s}$ after onset). In control trials, stimulation of 0 amplitude was delivered. We then used linear regression to fit post-firing rates according to the following equation:

$$
r_{\text {post }}=\beta_{0}+\beta_{1} \times r_{\text {pre }}+\beta_{2} \times s+\beta_{3} \times r_{\text {pre }} \times s,
$$

where $r_{\text {pre }}$ and $r_{\text {post }}$ are the pre and post firing rates of each unit, respectively, and $s$, the photostimulation term, is equal to 1 in photostimulated trials and 0 in control trials (see Fig. $3 A$ ) or to the photostimulation frequency (see Fig. $3 B$ ). Note that $\beta_{2}$ and $\beta_{3}$ correspond to the subtractive and divisive components of inhibition, respectively.

We also tested whether the inhibition of individual units scaled with baseline firing rate fluctuations in a similar manner. We first gathered all the pairs of firing rates comprising pre ( 4 to $0 \mathrm{~s}$ before photostimulation onset) and post ( 0 to $4 \mathrm{~s}$ after) in both stimulated and control trials. To avoid "flooring" effects attributable to the fact that neuronal firing cannot reach negative values, we discarded data points in which the post firing rate was 0 . We then normalized all firing rates by dividing all values by the maximum pre value. Finally, we used linear regression to fit post firing rates. The model used was identical to the one described above (Eq. 1), only that here individual units were fitted separately, and data points correspond to individual trials instead of individual units.

Because this analysis relies on the existence of significant temporal correlations in the firing rates of units within the relevant time window, we only included units that displayed a significant correlation between pre and post firing rates (i.e., units with significant $\beta_{1}$ values; $n=14$ neurons of 38 inhibited neurons). Failure to meet this criterion would suggest that the firing-rate fluctuations of the unit are too rapid, making the comparison between pre and post firing rates meaningless.

A similar analysis was performed to measure the scaling of odor responses with baseline firing rates (see Fig. 7) and their interaction with photostimulation. The analysis was similar to that of spontaneous activity described above, with one exception: the 4 s post time window was aligned on odor onset ( $1 \mathrm{~s}$ after photostimulation onset). To model the relation between prestimulation and poststimulation firing rates, their modulation by odors and photostimulation, and the interaction between the two, we used the following equation:

$$
\begin{aligned}
r_{\text {post }}=\beta_{0}+\beta_{1} \times r_{\text {pre }}+\beta_{2} \times x+ & \beta_{3} \times r_{\text {pre }} \times s+\beta_{4} \times r_{\text {pre }} \times x+\beta_{5} \\
& \times s \times x+\beta_{6} \times r_{\text {pre }} \times s \times x .
\end{aligned}
$$

Here, $x$ is the odor term and is equal to 1 in trials in which odors presented and 0 otherwise. This analysis was mainly aimed at determining whether the effects of 5-HT and odor stimuli were independent or not, as reflected in the magnitude of the interaction terms $\beta_{5}$ and $\beta_{6}$. Note that, because we found that the subtractive term for photostimulation trials was 0 (see Fig. 4), we omitted this term from the model to decrease the number of free parameters of the model. A similar analysis using a similar model that included this term showed qualitatively similar results.

Breathing was monitored continuously during recording experiments using a piezoelectric strap (Kent Scientific) wrapped around the animal's chest. During inspiration, expansions of the thorax result in sharp deflections in the recorded signal (Spors et al., 2006; Gautam and Verhagen, 2012). Individual sniffs were defined as starting $50 \mathrm{~ms}$ before the peak of the deflection (to avoid splitting single inhalations into separate cycles) and ending $50 \mathrm{~ms}$ before the consecutive peak (for example, respiration data; see Fig. $8 A$ ).
To test for sniff phase locking of firing in individual units during odor presentation, we first computed the sniff phases of all action potentials occurring during the six sniffs after odor onset $(\sim 2 s)$. We then tested whether firing was locked significantly to sniffing using the Rayleigh test for non-uniformity of circular data. Only neuron-odor pairs that showed significant $(p<0.05)$ phase locking during both control and photostimulated conditions were analyzed further. Finally, we compared the average phase and magnitude of the sniff-aligned firing rate distributions during control and photostimulated conditions.

\section{Results}

\section{DRN 5-HT photostimulation reduces the spontaneous} activity of aPC neurons in vivo

To study the effects of 5-HT release in vivo, we recorded extracellular single-unit activity in the aPC in anesthetized SERT-Cre mice. The mice were infected previously (2-6 weeks) with AAV2/ 1-Flex-ChR2-YFP to express the light-sensitive channel ChR2 in 5-HT neurons (Fig. 1A), as described previously (Dugué et al., 2014). Figure $1 B$ shows an example unit whose spontaneous firing was suppressed after DRN 5-HT photostimulation.

A comparison between the spontaneous activity of aPC neurons recorded in the presence and absence of DRN photostimulation ( $3 \mathrm{~s}$ trains of $10 \mathrm{~ms}$ light pulses at $10-30 \mathrm{~Hz}, 5 \mathrm{~mW}$ ) showed prominent inhibition of neuronal activity (baseline firing rate, $5.42 \pm 0.76 \mathrm{~Hz}$; fraction of baseline firing rate after photostimulation, $56 \pm 8 \% ; n=63 ; p<0.001$, Wilcoxon's signed-rank test; Fig. 1C). We used ROC analysis both to test for the significance of photostimulation-induced changes in firing rates and to derive an MI (see Materials and Methods). MI values range from -1 to 1 , with positive values indicating enhancement and negative values indicating suppression. Of 63 units, 38 (60\%) showed significant suppression of firing, whereas only three neurons $(5 \%)$ showed increased firing. Overall, the distribution of MI values was skewed heavily toward negative values (average MI, $-0.49 \pm$ 0.05; Fig. 1D).

The time course of photostimulation-induced suppression of aPC firing was rapid, reaching significant levels within $200 \mathrm{~ms}$ (161 $\pm 48 \mathrm{~ms}$, median $\pm \mathrm{SEM} ; n=38$; data not shown). In a subset of units tested with a range of frequencies $(1-30 \mathrm{~Hz})$, the 5-HT photostimulation effect was also dose dependent, with higher stimulation frequencies resulting in a more prominent effect ( $p<0.001$, Kruskal-Wallis test; $n=15$; Fig. $2 A, B)$. By varying the duration of photostimulation for a subset of units, we found that, when calculated within a fixed time window corresponding to the longest stimulus, the decrease in firing was linearly proportional to the fraction of photostimulation time within the measurement window (fitted slope, $-0.80 ; n=5 ; p<$ 0.001 ; Fig. $2 C, D$ ). This indicates that, after its rapid onset, the effect of photostimulation was constant throughout the entire period of photostimulation.

\section{Divisive effect on spontaneous firing}

We next asked whether the magnitude of inhibition of spontaneous activity depended on the firing rate of the recorded unit. Figure $3 A$ shows, for each inhibited neuron, the firing rate during photostimulation and a time-matched period in control trials as a function of its baseline firing rate calculated during a $4 \mathrm{~s}$ time window just before photostimulation onset. We found that firing rates during DRN photostimulation were correlated strongly with baseline firing rates in a proportional or divisive manner, i.e., the larger the baseline firing rate, the larger the 5-HT-induced inhibition. We used a linear regression to model the divisive and subtractive components of inhibition (see Eq. 1). Consistent with a divisive effect on spontaneous firing, we found that the coeffi- 
cient of the term corresponding to an interaction between firing rates before and during photostimulation ( $\beta_{3}$ in Eq. 1 ) was significantly less than 0 [fitted value, $-0.58 ; 95 \%$ confidence interval (CI), -0.64 to $-0.52 ; p<0.001]$, whereas $\beta_{2}$, the coefficient of the additive photostimulation term was not (fitted value, $-0.22 ; 95 \% \mathrm{CI},-0.70$ to $0.26 ; p>0.05)$. Additionally, the slope was dependent on the frequency of photostimulation (Fig. 3B), with higher photostimulation frequencies yielding a more prominent change in slope (fitted coefficient of divisive term, -0.024 ; 95\% CI, -0.02 to $-0.028 ; p<0.001)$.

These observations show an average divisive effect of 5-HT action on spontaneous firing. One possible explanation for this effect is that the magnitude of inhibition correlates with the average baseline activity of an individual neuron but that the firing rate of each neuron is reduced by a fixed amount, regardless of its current state of activity. Alternatively, the amount of inhibition received by each neuron may actually covary with instantaneous firing rate fluctuations on a moment-by-moment (trialby-trial) basis. To distinguish between these alternatives, we analyzed the effect of photostimulation on instantaneous firing rates by fitting a linear model for each unit, in which we predict firing rates immediately before and after photostimulation onset (Eq. 1; Fig. 4B). Figure $4, A$ and $C$, shows an example unit in which the fluctuations in spontaneous firing rate were correlated strongly between the two time periods. Consistent with a divisive mechanism, we found that the slope of the fitted linear curves was reduced significantly in the presence of 5-HT and that the intercept was not, both in the example unit and across the population of neurons (fitted coefficient of divisive term, $-0.59 \pm 0.09$; $p<0.001$; fitted coefficient of subtractive term, $-0.025 \pm 0.04 ; n=14 ; p>$ 0.05 , Wilcoxon's sign-rank test with Bonferroni's correction for multiple comparisons; Fig. 4D). Thus, 5-HT appears to have a divisive scaling effect not just on a neuron-by-neuron basis but also on the momentary firing rates of individual neurons.

\section{DRN 5-HT stimulation inhibits aPC activity during odor presentation}

Next, we examined the effect of DRN photostimulation on odorevoked neural activity in the aPC. To this end, anesthetized mice were presented with odorants using a custom-built olfactometer (see Materials and Methods). Odors evoked a significant repermutation test).

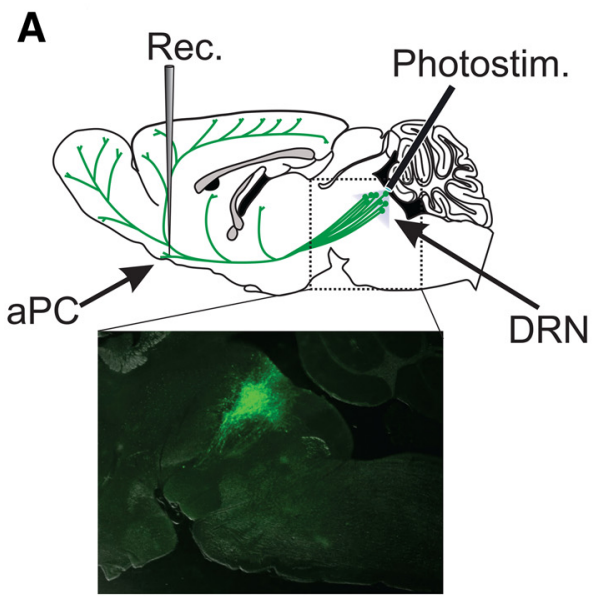

C

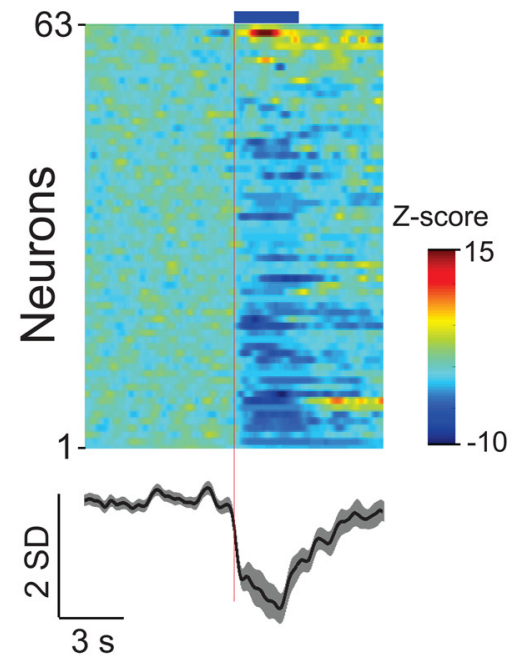

B

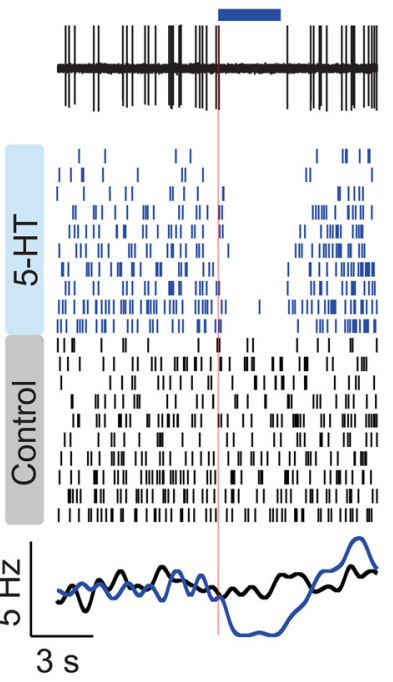

D

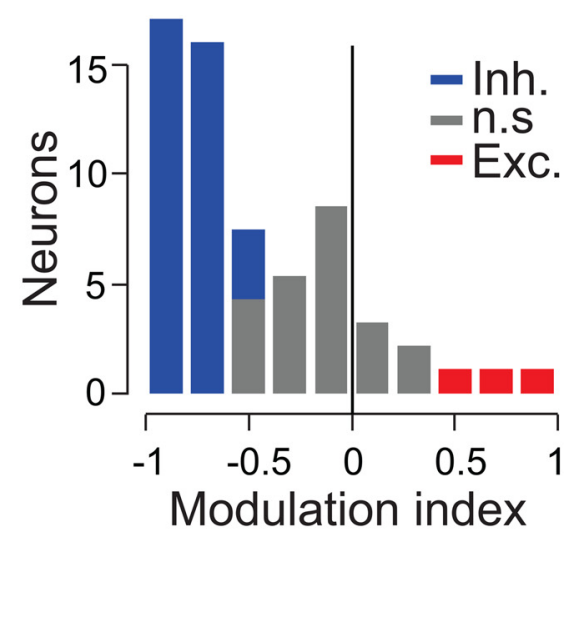

Figure 1. DRN 5-HT photostimulation results in a prominent suppression of aPC spontaneous activity. $A$, Top, Schematic of the experimental setup. ChR2-expressing DRN neurons were photostimulated with blue light using an optical fiber. A recording electrode (Rec.) was placed in the aPC to monitor single-unit activity and its modulation by photostimulation (Photostim.). Bottom, Example sagittal section taken from a SERT-Cre transgenic mouse infected previously with AAV2/1-Flex-ChR2-YFP. Only cells expressing the SERT also express yellow fluorescent protein (YFP) and are therefore fluorescent. $\boldsymbol{B}$, Example of spontaneous activity of an aPC unit and its response to DRN photostimulation. Top, Single-trial raw data aligned on photostimulation onset (blue horizontal bar, $5 \mathrm{~mW}, 10 \mathrm{~ms}$ pulses at $20 \mathrm{~Hz}$, the stimulation lasted $3 \mathrm{~s}$ ). Middle, Raster plot in which each tic is a single-unit spike and each row represents a single trial. Trials were interleaved randomly but are shown sorted here for display purposes. Blue ticks correspond to photostimulated trials and black to control. The red line marks photostimulation onset. PSTHs of control and photostimulated trials (smoothed using a Gaussian filter with $250 \mathrm{~ms} \mathrm{SD}$; bottom). C, Top, Heat map plot of the population PSTHs. The z-scored PSTH of each neuron is presented as a row ( $n=63$ neurons) aligned on photostimulation onset. Neurons were sorted according to their modulation by photostimulation. Bottom, Grand average $z$-scored PSTH of all neurons during photostimulated trials (shaded patches around the mean represent \pm SEM). Across the population of neurons, photostimulation frequencies varied between 5 and $30 \mathrm{~Hz}$, in cases in which a unit was stimulated with more than one frequency, the PSTH corresponding to the highest frequency is shown. $\boldsymbol{D}, \mathrm{ROC}$-based Mls for all recorded neurons (see Materials and Methods). Blue bars represent significantly inhibited units (Inh.), red significantly excited (Exc.), and gray not significantly modulated (n.s.; $p<0.05$,

sponse in 33 neurons (52\%), of which 25 (40\%) were also inhibited by light. Although some aPC neurons were inhibited by odors, all the units that were both odor responsive and light modulated exhibited increased firing rates during odor delivery and decreased firing rates during DRN photostimulation. Figure $5 A$ shows an example odor-responsive neuron in which both spontaneous and odor-evoked activity were inhibited by DRN photostimulation. Thus, 5-HT photostimulation had an overall 
A

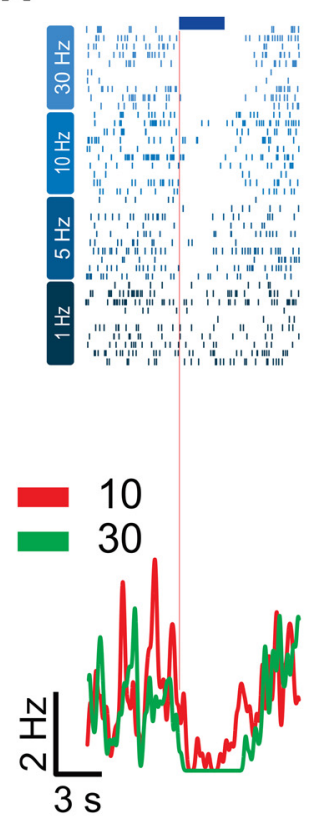

C

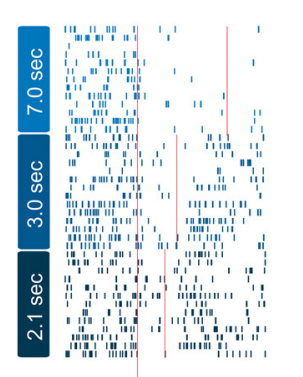

2.1

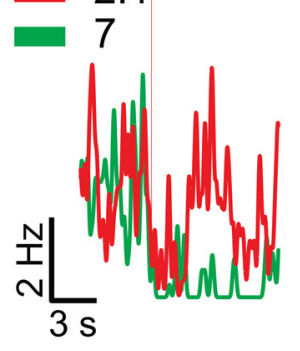

B
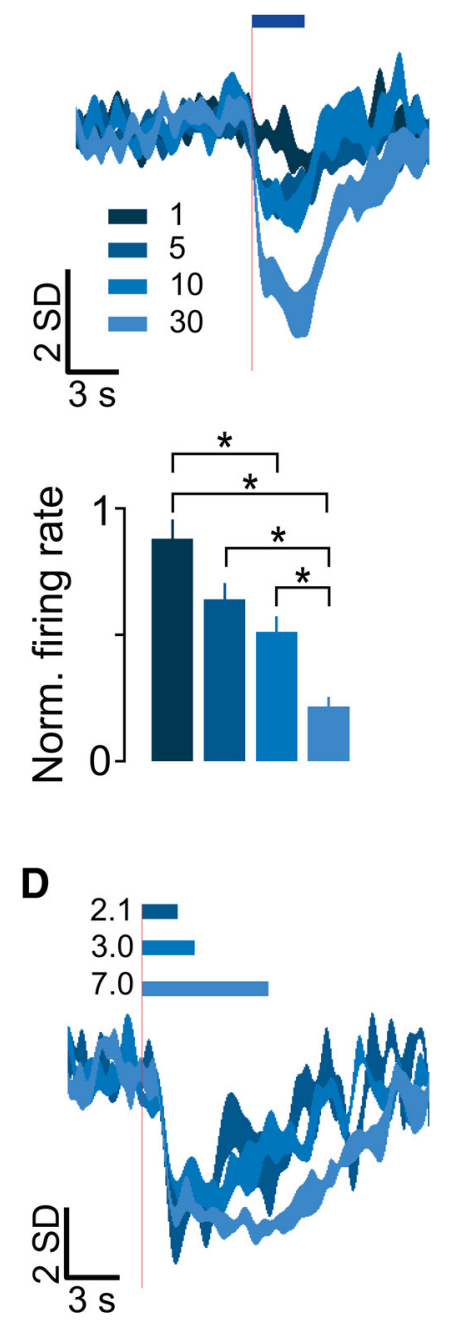

Figure 2. Dose-dependent suppression of aPC spontaneous activity. $\boldsymbol{A}$, Relationship between photostimulation frequency and modulation magnitude in one example unit. Top, Raster plot of single-unit spikes with trials sorted by photostimulation frequency. The different colors represent different photostimulation frequencies, which are also indicated to the left of the plot. The red line marks photostimulation onset. PSTHs of $10 \mathrm{~Hz}$ (red) and $30 \mathrm{~Hz}$ (green) photostimulated trials (smoothed using a Gaussian filter with 250 ms SD; bottom). B, Relationship between photostimulation frequency and modulation magnitude in all significantly inhibited units ( $n=15$ ). Top, Average normalized PSTHs (shaded patches represent mean \pm SEM). Bottom, Dose-response plot. Each bar corresponds to the normalized firing rates for the different photostimulation frequencies (same color scheme as in $\boldsymbol{A}$ and top panel). Error bars represent SEM, and asterisks denote significant differences between pairs of photostimulation frequencies assessed using Tukey-Kramer post hoc comparisons after a Kruskal-Wallis test. C, Top, Relationship between photostimulation duration and modulation magnitude in one example unit. Raster plot of single-unit spikes with trials sorted according to photostimulation duration. The different colors represent different photostimulation durations, which are also indicated to the left of the plot. The red lines delineate photostimulation onset and offset.

inhibitory effect on firing during odor presentation, but we wondered whether this effect was similar to that observed on spontaneous activity or not. If inhibition shows the same divisive effect it showed on spontaneous firing, it should also cause a proportional reduction in the odor-evoked component of the response. Conversely, if 5-HT photostimulation affects spontaneous and odor-evoked firing differently, this may not hold. In particular, if spontaneous firing were affected selectively, the odor response could be unaffected.

To reveal the effect of 5-HT photostimulation during odor stimulation more precisely, we subtracted the average PSTH for odor alone (Fig. 5B1) from the average odor PSTH for odor with photostimulation (Fig. 5B2) to form a difference PSTH that represents the effect of photostimulation (Fig. 5B3). We found a striking similarity between the photostimulation effect measured using this difference during odor stimulation (Fig. 5B3) and that measured during spontaneous activity (Fig. 1C).

Across the population of units $(n=63)$, MI values in the presence and absence of odors were very similar (Fig. 5C), and the sign of modulation of spontaneous activity and odor-evoked activity was consistent for all neurons. Moreover, the magnitude of modulation (measured as the absolute firing rate change relative to the corresponding control, nonstimulated condition) induced by photostimulation in the presence or absence of odors was similar (fitted slope, 1.12; $n=63$; slope different from $0, p<$ 0.001 ; Fig. $5 D$ ). In summary, these analyses showed that the amount of photostimulation effect on aPC firing does not depend on the presence or absence of an odor stimulus.

\section{DRN 5-HT stimulation yields subtractive inhibition with respect to odor-evoked firing}

Because odor stimuli increased the firing rates but did not increase inhibition, these data suggested that DRN 5-HT modulation is not purely divisive in the presence of an odor. To verify this, we next performed a similar subtractive analysis to reveal the effect of photostimulation from the perspective of the odor response itself. We restricted the analysis to those neurons that were both excited by odors and inhibited by DRN photostimulation $(n=25)$. To reveal the quantitative effect of 5 -HT photostimulation-mediated inhibition on the odor response, we subtracted the average response PSTH for photostimulation during spontaneous activity from the PSTH for photostimulation during odor presentation (Fig. 6A). The resulting difference could then be compared with the odor-evoked response in the absence of photostimulation. This analysis revealed that the component of firing driven by the odor was unaltered by photostimulation (Fig. 6B). This result held true not only for the population average odor-evoked PSTHs but also when comparing the individual odor responses of each neuron with or without photostimulation (Fig. 6C,D). In other words, although photostimulation reduced firing rates during odor presentation (average reduction in firing rates after photostimulation, $3.7 \pm 0.78 \mathrm{~Hz}$; $n=25 ; p<0.001$, Wilcoxon's sign-rank test; Fig. $6 E$ ), this effect was entirely accounted for by the loss of spontaneous (baseline)

\section{$\leftarrow$}

Bottom, PSTHs of $2.1 \mathrm{~s}$ (red) and $7.0 \mathrm{~s}$ (green) photostimulation duration trials (smoothed using a Gaussian filter with $250 \mathrm{~ms}$ SD). D. Relationship between photostimulation duration and modulation magnitude in all significantly inhibited units $(n=5)$. Top, Average normalized PSTHs (shaded patches represent mean \pm SEM). Bottom, Dose-response curve. Normalized firing rate (fraction of control) is plotted as a function of the photostimulation duration. Error bars represent SEM. Black line is the regression line. The correlation coefficient and $p$ value of the regression are indicated below. 
spikes. Thus, as seen above (Fig. 5D), the amount of inhibition was not significantly different between baseline and odor trials (average difference in inhibition between odor-evoked and baseline firing rates, $0.056 \pm 0.64 \mathrm{~Hz} ; n=25 ; p>0.5$, Wilcoxon's sign-rank test; Fig. $6 F$ ).

To exclude the possibility that the lack of effect on odor responses is attributable to saturation of responses to odors, we examined the effect of 5-HT photostimulation on responses elicited by multiple odorants. In neurons that responded to more than one odor, the same result held for both the odorant eliciting the largest response ("best odor") and for other odorants eliciting weaker responses (Fig. $6 G, H)$. Although both odor responses were suppressed after photostimulation (average reduction in best/second odorevoked firing, $2.25 \pm 0.40 \mathrm{~Hz} / 1.85 \pm 0.33$; $n=10 ; p<0.01$ for both, Wilcoxon's sign-rank test; Fig. 6I), the amount of inhibition did not differ between the two odors and baseline inhibition $(p>0.8$, Kruskal-Wallis test; $n=10$; Fig. $6 J$ ).

Together, these results show that, whereas DRN 5-HT stimulation effects on spontaneous activity were always proportional to the instantaneous spontaneous firing rate, i.e., divisive, they were independent of additional firing caused by odor presentation, i.e., subtractive.

\section{Divisive effect on baseline firing during odor presentation}

The divisive effect on spontaneous activity and lack of effect on odor responses suggests that the net odor response consists of two independent components: a first component that is continuously present and is divisively inhibited by 5 -HT and a second component that is recruited by odor stimuli and is independent of DRN activation. If this dual-component model is correct and if trial-by-trial fluctuations ("noise") between these two components are uncorrelated or weakly correlated, then a trial-by-trial analysis ought to reveal the divisive effect of 5-HT stimulation relative to baseline activity and an additive odor-evoked component, unaffected by photostimulation (Fig. 7). To test this hypothesis, we used a regression analysis similar to the one shown in Figure 4, this time analyzing the effect of photostimulation on instantaneous firing rates by predicting, for each unit-odor pair, its firing rates immediately before photostimulation onset to those immediately after odor onset. Figure $7 A$ shows an example
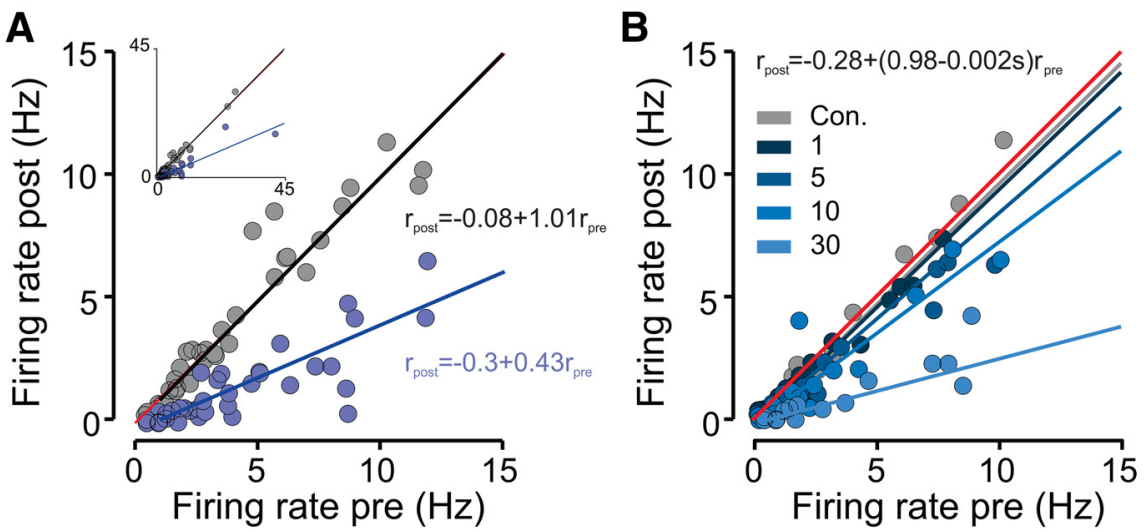

Figure 3. Suppression of average aPC spontaneous activity linearly scales with baseline firing rate. $\boldsymbol{A}$, Scatter plot comparing firing rates under control and photostimulated trials for all significantly inhibited units $(n=38)$. A linear regression fit is superimposed. Two outlying points were excluded from the main plot for clarity purposes and are shown in the inset. The linear regression equations are shown next to the corresponding regression lines. $\boldsymbol{B}$, Same as $\boldsymbol{A}$ for a subpopulation of neurons that were photostimulated with $1,5,10$, and $30 \mathrm{~Hz}(n=15)$. Con., Control.
A
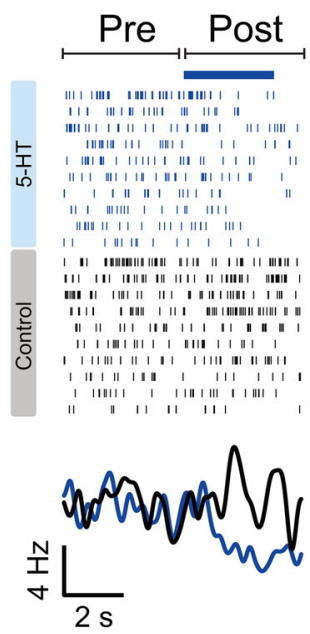

C

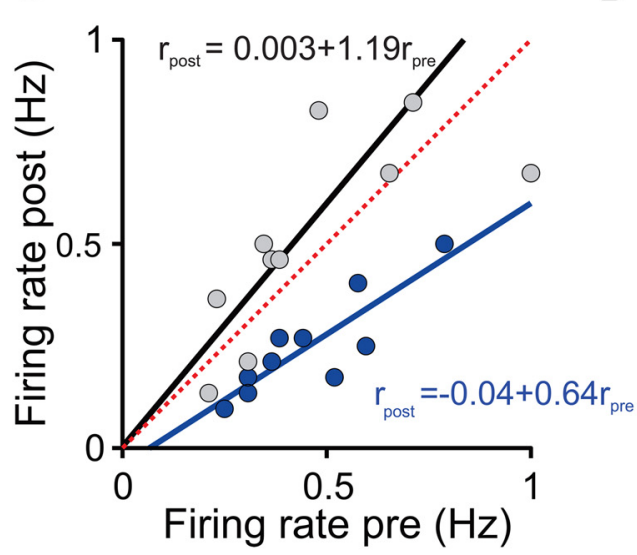

D

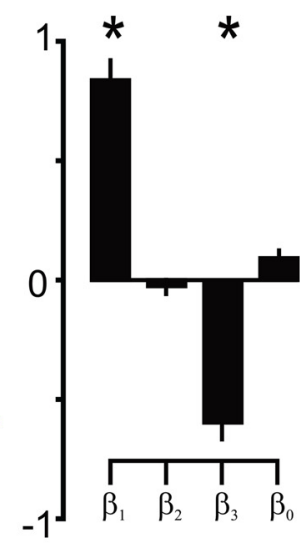

Figure 4. Suppression of instantaneous aPC spontaneous activity linearly scales with baseline firing rate. $\boldsymbol{A}$, Raster plot and PSTH (smoothed using a Gaussian filter with 250 ms SD) of single-unit spikes with trials sorted according to photostimulation versus control and by baseline firing rate. Blue ticks belong to photostimulated trials and black to control, respectively. Blue horizontal line delineates photostimulation delivery. $\boldsymbol{B}$, Scheme of the linear model used to predict, for each unit, its post firing rate as a function of pre firing rate and photostimulation condition. Div., Divisive; Sub., subtractive. $\boldsymbol{C}$, Single-trial correlation between firing rates before and after photostimulation onset for the example unit shown in $\boldsymbol{A}$ (blue circles). A similar comparison was made for control, nonstimulated trials (gray circles). Solid lines indicate linear regression curves. Corresponding linear regression equations are shown as well. $\boldsymbol{D}$, The vales of the average regression coefficients $(n=14)$. Error bars represent SEM; ${ }^{*} p<0.05$, Wilcoxon's sign-rank test with Bonferroni's correction for multiple comparisons. 
A

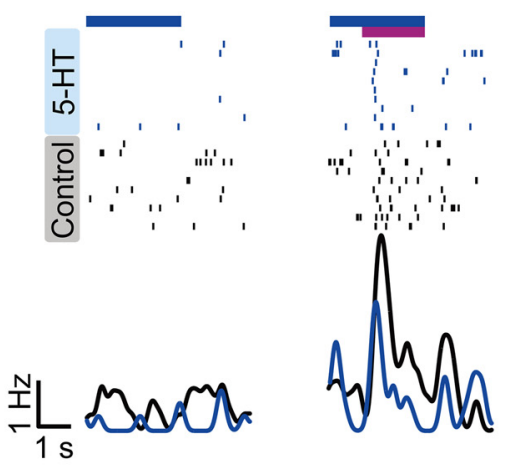

B

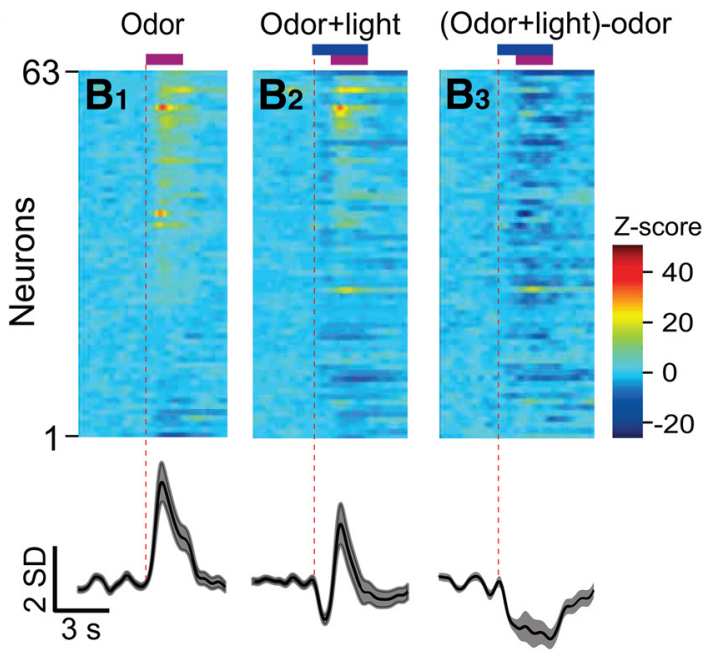

C

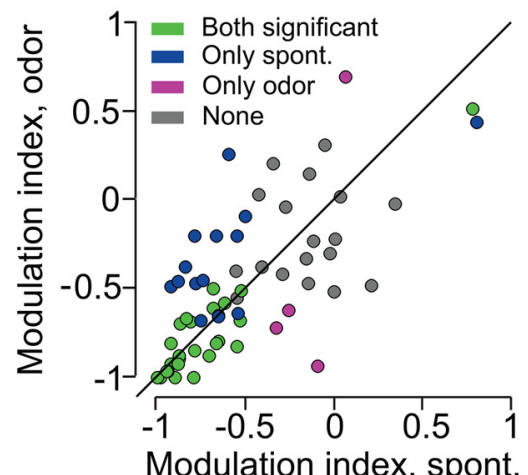

D

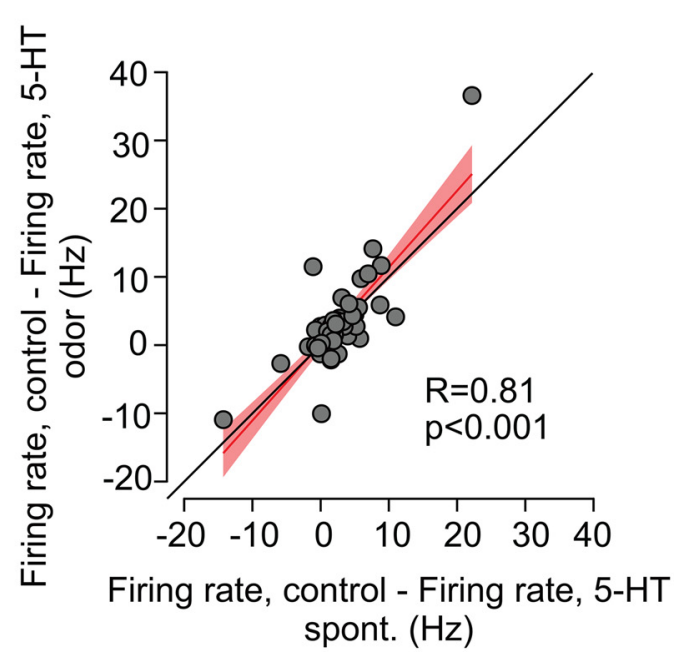

Figure 5. DRN 5-HT photostimulation inhibits aPC activity during odor presentation. $A$, Example raster plot (top) and PSTH (bottom) of a single aPC neuron in spontaneous trials (left) and in response to odor (right). Blue and magenta horizontal lines delineate photostimulation and odor delivery, respectively. PSTHs were smoothed using a Gaussian filter with 25 ms SD. $\boldsymbol{B}$, Top, Heat maps of the population odor responses $(n=63)$. Each row is the normalized PSTH of one unit. $\boldsymbol{B} 1$, Control trials; $\boldsymbol{B 2}$, photostimulation trials; $\boldsymbol{B} 3$, the difference between the $\boldsymbol{B} \mathbf{1}$ and $\boldsymbol{B} \mathbf{2}$ plots. Bottom, The corresponding grand averages. C, Scatter plot of photostimulation Mls for spontaneous firing (blank stimulus) and during odor presentation. Green circles represent significantly inhibited units under both odor and spontaneous (blank) conditions, blue only spontaneous conditions, magenta only odor conditions, and black not significantly modulated ( $p<0.05$, permutation test). D, Scatter plot and linear regression fit of the change in firing rate for spontaneous firing (blank stimulus) and during odor presentation. The change is measured as the difference between the average firing rate during the stimulus period and the corresponding nonstimulated control (see Materials and Methods). The correlation coefficient and $p$ value of the regression are indicated below. Spont., Spontaneous.

odor-responsive unit. Both pre-photostimulation firing rates and poststimulation responses, reflecting odor and photostimulation contributions, fluctuated substantially from trialto-trial. We performed a linear fit to describe the relationship between prestimulation and poststimulation firing rates across trials (see Eq. 2; Fig. 7B,C). As predicted from the two-component model, odor delivery had an additive effect on firing, whereas photostimulation had a divisive effect. Importantly, we did not find significant interactions between the two components (fitted coefficients of both subtractive and divisive odor-photostimulation interaction terms, -0.02 and 0.01 ; $95 \%$ CIs, -0.20 to 0.16 and -0.53 to 0.55 ; values correspond to $\beta_{5}$ and $\beta_{6}$ in Eq. 2, respectively; $p>0.05$ for both). Across the population of neuron-odor pairs, we found the same result, namely that odors exerted an additive effect on firing rates (fitted coefficient of additive term, $-0.29 \pm 0.06$; $p<0.001$; fitted coefficient of multiplicative term, $-0.26 \pm$ $0.09 ; p>0.05$, Wilcoxon's sign-rank test with Bonferroni's correction for multiple comparisons; $n=14$; values correspond to $\beta_{2}$ and $\beta_{4}$ in Eq. 2; Fig. $7 D$ ), photostimulation exerted a divisive effect (fitted coefficient of divisive term, $-0.63 \pm 0.05 ; p<0.001$; value corresponds to $\beta_{3}$ in Eq. 2 ; Fig.
$7 D)$, and neither of the interaction terms were significantly different from 0 (fitted coefficients of subtractive and divisive odor-photostimulation interaction terms, $-0.04 \pm 0.06$, and $0.09 \pm 0.11$, respectively; $p>0.05$ for both; values correspond to $\beta_{5}$ and $\beta_{6}$ in Eq. 2; Fig. $7 D$ ).

\section{DRN 5-HT stimulation preserves sniff phase coupling}

aPC neurons show strong modulation of their firing rates by the respiration (sniffing) cycle (Wilson, 1998; Litaudon et al., 2003), which may be important for odor coding (Kepecs et al., 2006). Therefore, we examined the effect of DRN 5-HT photostimulation on odor-evoked responses analyzed with respect to the sniff cycle. Figure $8 A$ shows an example unit whose firing was locked strongly to respiration under both photostimulation and control conditions. Sniff-averaged firing rates decreased monotonically with time after odor onset. We took advantage of this drop in amplitude across sniffs to test whether photostimulation has a divisive or subtractive effect described across odors and neurons. We found that the effect on firing rates across consecutive sniffs was subtractive, i.e., all were inhibited by a similar magnitude (Fig. $8 B$ ), consistent with the observations on odor responses in general (Figs. 5-7). 
A

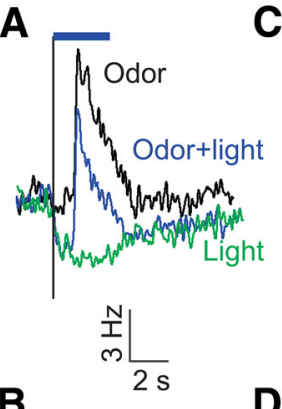

B

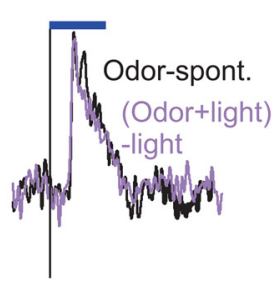

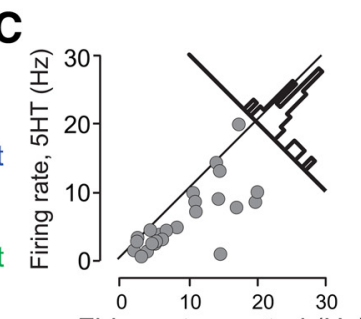

Firing rate, control $(\mathrm{Hz})$

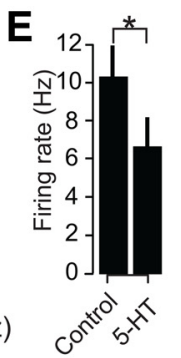

$\mathbf{F}$

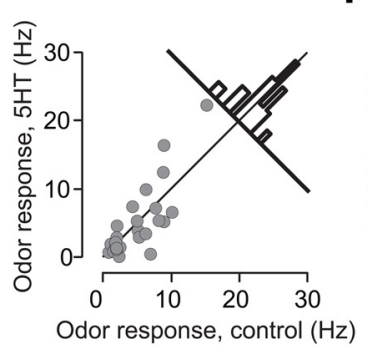

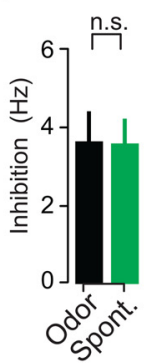

G

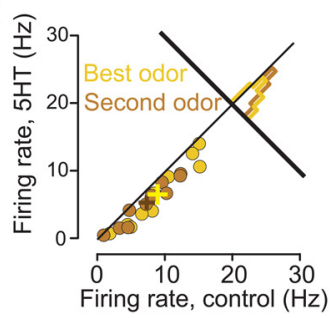

H

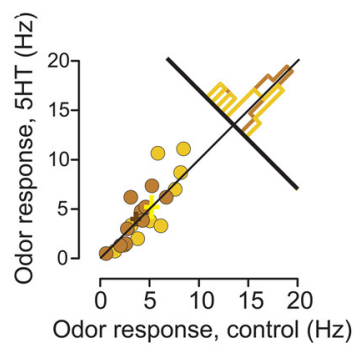

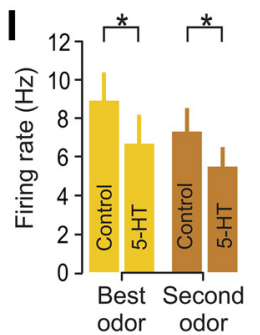

J

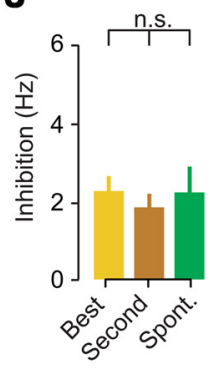

Figure 6. Baseline inhibition accounts for odor response inhibition. $\boldsymbol{A}$, Mean PSTHs of all neurons showing significant odor responses and light modulations in the absence (black line) and presence (blue line) of DRN photostimulation $(n=25)$. The green line represents the average PSTH after DRN photostimulation in the absence of odorant presentation. In cases in which a unit was stimulated with more than one odor, the PSTH corresponding to the strongest response is used $(\boldsymbol{A}-\boldsymbol{F})$. $\boldsymbol{B}$, Mean PSTHs of all neurons showing significant odor responses and light modulations in the absence (black line) and presence (purple line) of DRN photostimulation after subtraction of the corresponding baselines (spontaneous PSTHs). C, Scatter plot comparing firing rates of activity during odor presentation in the absence and presence of photostimulation. Each point corresponds to a single unit $(n=25)$. Bar histogram shows the distribution of differences between photostimulated and control firing rates across the population. The distribution is shifted away from the main diagonal toward the bottom right, indicating inhibition during photostimulation. $D$, Scatter plot comparing odor responses (difference between firing rates and baseline) in the absence and presence of photostimulation. Each point corresponds to a single unit ( $n=25$ ). Bar histogram shows the distribution of differences between photostimulated and control firing rates across the population. The distribution is centered around the main diagonal, indicating no effect of photostimulation on odor responses after accounting for the effect of DRN activation alone. $\boldsymbol{E}$, Bar graphs comparing firing rates in the presence and absence of photostimulation. Error bars represent $S E M$; ${ }^{*} p<0.001$, Wilcoxon's sign-rank test. $\boldsymbol{F}$, Bar graphs comparing photostimulation-evoked decrease in firing in the presence and absence of odor stimulation. Error bars represent SEM; $p>0.5$, Wilcoxon's sign-rank test. $\mathbf{G}$, Scatter plot comparing firing rates during odor presentation for odors evoking maximal responses (yellow) and a second odor (brown), in the absence and presence of photostimulation. Each point corresponds to a single neuron- odor pair ( $n=10$ neurons). Bar histograms show the distribution of differences between photostimulated and control firing rates across the population. $\boldsymbol{H}$, Scatter plot comparing firing rates of odor responses for odors evoking maximal responses (yellow) and a second odor (brown), in the absence and presence of photostimulation ( $n=10$ neurons). Bar histograms as in G. I, Bar graphs comparing firing rates in the presence and absence of photostimulation for both best (yellow) and a second odor (brown). Error bars represent SEM; ${ }^{*} p<0.001$ for both odors, Wilcoxon's sign-rank test. $J$, Bar graphs comparing photostimulation-evoked decrease in firing in the presence of the two odors and baseline conditions. Error bars represent SEM; $p>0.8$, Kruskal-Wallis test. Spont., Spontaneous.

We did not find an effect of photostimulation on sniff frequency under baseline conditions (average difference in sniff frequency between photostimulated and baseline conditions, $0.015 \pm 0.02 \mathrm{~Hz} ; n=25 ; p>0.05$, Wilcoxon's sign-rank test; Fig. $8 D, E)$, and, although we did observe a modest increase in sniff frequency after odor presentation (average difference in sniff frequency between odor and baseline conditions, $0.071 \pm$ $0.02 \mathrm{~Hz} ; n=25 ; p<0.05$, Wilcoxon's sign-rank test; Fig. $8 F, G)$, this effect was comparable during control and photostimulated trials (average difference in sniff frequency between photostimulated and control trials during odor presentation, $0.0078 \pm 0.045 \mathrm{~Hz} ; n=25 ; p>0.05$, Wilcoxon's sign-rank test). To test the effect of photostimulation on phase coupling between neuronal firing and respiration, we restricted our analysis to units inhibited significantly by light that also responded to odor stimulation in a sniff-locked manner in both control and photostimulated trials $(n=21$ neuron-odor pairs). Despite the marked decrease in firing rates, we found no effect of DRN photostimulation on the preferred sniff phase of responses across the population (average difference in preferred sniff phase, $0.083 \pm 0.12$ radians; $n=21 ; p>0.5$, Wilcoxon's sign-rank test; Fig. $8 H, I)$. Photostimulation did cause a small but significant increase in the strength of coupling between firing and respiration (average magnitude of sniff coupling in control vs photostimulation conditions, $0.33 \pm 0.041$ vs $0.39 \pm 0.045 ; n=21 ; p<0.05$, Wilcoxon's sign-rank test; Fig. $8 \mathrm{~J}, \mathrm{~K}$ ).

\section{Discussion}

The main finding of this study is that specific activation of 5-HT neurons in vivo rapidly modulates the activity of olfactory cortex (aPC) neurons by suppressing spontaneous firing while sparing odor-evoked firing. The effects on spontaneous firing were divisive with respect to moment-by-moment fluctuations in spontaneous activity (Fig. 4), but because the odor-dependent component was unaffected (Fig. 6), they were subtractive with respect to the net odor response (Fig. 7). Respiration phase coupling was enhanced but its phase was unaltered (Fig. 8). These findings present novel evidence for the role of serotonergic neuromodulation in sensory processing and indicate that it acts on fast timescales to alter the balance between different sources of neural activity in sensory systems.

\section{Functional implications: divisive inhibition of spontaneous activity}

Remarkably, the effects of DRN 5-HT neuron activation were consistent with a simple dual-component model in which action potentials in sensory cortex originate from two independent sources: (1) a background or spontaneous source that fluctuates independently of sensory input and is modulated by 5 -HT; and 


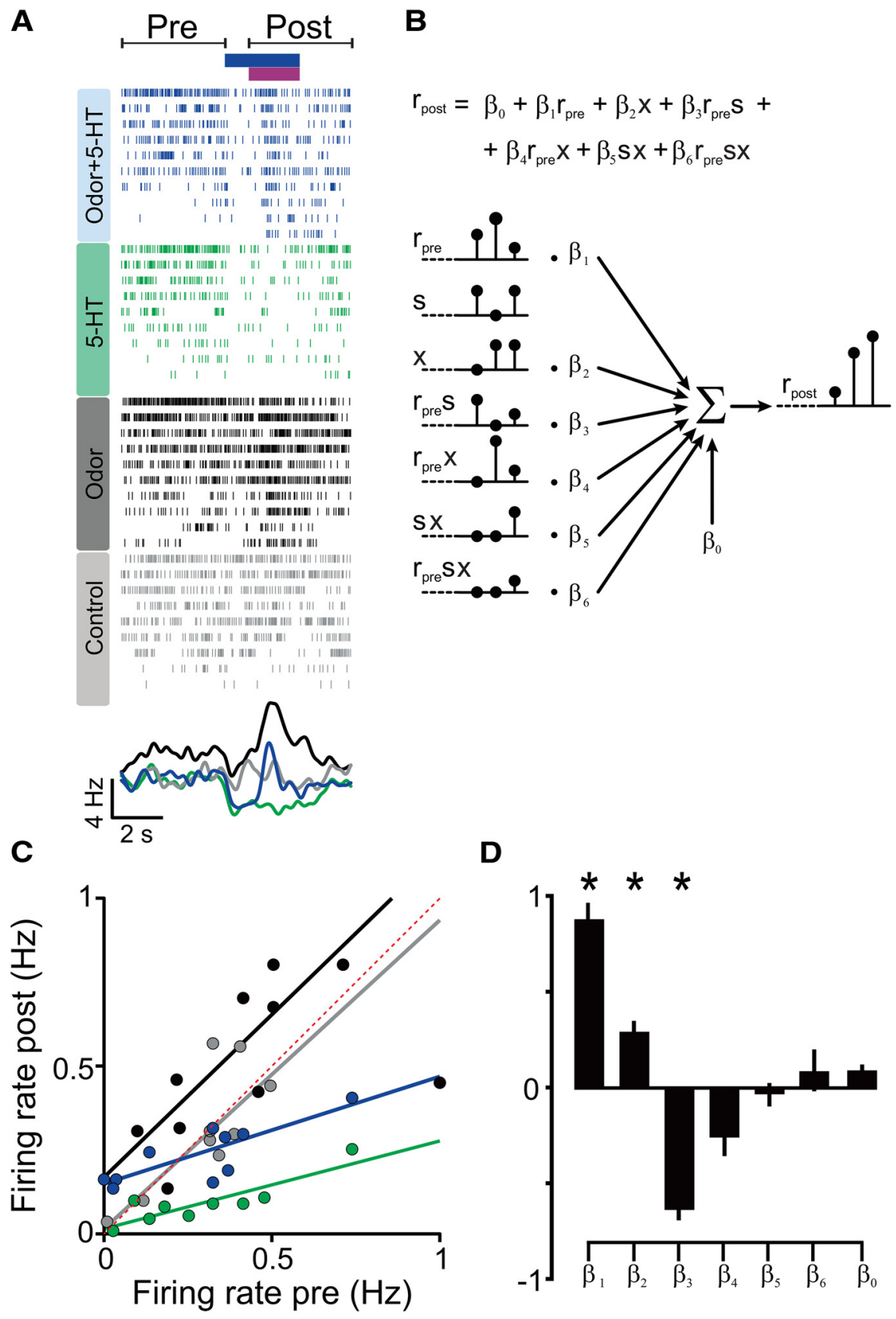

Figure 7. Modulation of instantaneous aPC odor responses linearly scales with baseline firing rate and is the sum of control odor responses and photostimulation-induced baseline suppression. $\boldsymbol{A}$, Raster plot and PSTH of single-unit spikes with trials sorted according to photostimulation and odor conditions and further sorted by baseline firing rate. Blue ticks belong to photostimulated plus odor trials, green to photostimulated trials, black to odor trials, and gray to control trials. Blue and magenta horizontal lines delineate photostimulation and odor delivery, respectively. $\boldsymbol{B}$, Scheme of the linear model used to predict, for each unit, its post firing rate as a function of pre firing rate, odor condition, photostimulation condition, and their interactions. $C$, Single-trial correlation between firing rates before and after photostimulation and/or odor onset for the example unit shown in $\boldsymbol{A}$. Solid lines indicate linear regression curves. The different colors represent different conditions as indicated in $\boldsymbol{A}$. $\boldsymbol{D}$, The values of average regression coefficients $(n=14)$. Error bars represent SEM; ${ }^{*} p<0.05$, Wilcoxon's sign-rank test with Bonferroni's correction for multiple comparisons.

(2) a stimulus-evoked source that is unaffected by $5-\mathrm{HT}$. The effects of 5-HT on spontaneous activity were multiplicative or divisive in nature. That is, they preserved the relative magnitude of activity both across the population of neurons and across individual neurons in time. Thus, 5-HT preserved the information content of spontaneous activity while changing only the gain. Such divisive effects can be compared with divisive normalization, a local operation thought to be a canonical neural computation (Carandini and Heeger, 2012).
The present study is one of the first systematic studies of the detailed effects of the activation of a neuromodulatory system on spontaneous and sensory-evoked single-unit activity in vivo. This was achieved by optogenetic activation of 5-HT DRN neurons. Although this is not exactly the same as endogenous activity, DRN neurons, like other neuromodulatory neurons, do display highly synchronous stimulus-locked firing in vivo (Ranade and Mainen, 2009). Therefore, it is highly relevant to understanding the endogenous systems-wide effects of 5-HT on sensory processing. Because the major neuromodulators not only share postsynaptic mechanisms but interact with one another at the physiological level, the effects described here are likely relevant to understanding the general computational architecture of the neuromodulatory systems (Dayan, 2012).

The functional implication of the divisive suppression of spontaneous activity hinges on the interpretation of spontaneous firing. If spontaneous activity reflects noise (Shadlen and Newsome, 1994), then by decreasing it, DRN 5-HT activation increases the signal-to-noise ratio, as has been proposed for other neuromodulators (Sara, 1985; Servan-Schreiber et al., 1990; Hasselmo et al., 1997). Alternatively, if spontaneous activity reflects information, such as an expectation or prior (Fiser et al., 2010; Berkes et al., 2011), DRN 5-HT activation decreases the relative weight of such priors relative to sensory data. In this context, it is significant that DRN 5-HT effects were strictly proportional (divisive) both across neurons and within individual neurons, as would be required to scale the information carried by spontaneous activity without corrupting it. Because the 5-HT system projects widely throughout the brain, the scaling of spontaneous versus evoked activity might reflect a more general function of 5-HT in the regulation of different sources of information for behavioral control (Yu and Dayan, 2002; Daw et al., 2005).

\section{Mechanisms of DRN 5-HT effects}

It will be interesting in future studies to address the mechanisms underlying these effects. When exogenously applied to cortical slices in vitro, 5 -HT can modulate synaptic transmission (Winterer et al., 2011), depolarize interneurons via 5-HT2a receptors leading to IPSPs in pyramidal neurons (Gellman and Aghajanian, 1993, 1994; Marek and Aghajanian, 1994), depolarize or hyperpolarize pyramidal neurons (Araneda and Andrade, 1991; Avesar and Gulledge, 2012), and decrease firing frequency adaptation in pyramidal neurons (Sheldon and Aghajanian, 1991). Optogenetic stimulation of ChR2-expressing DRN axons in vitro can excite hip- 
A

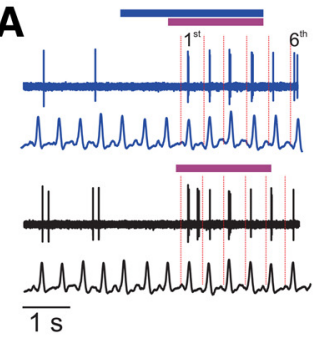

D

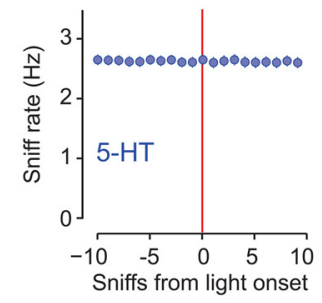

H

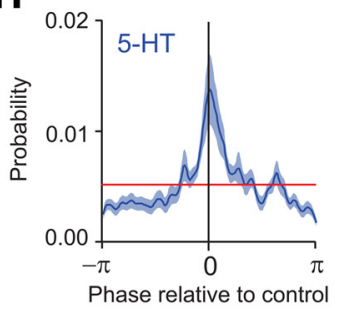

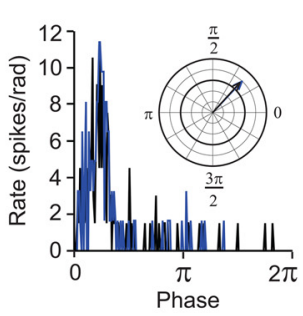

B

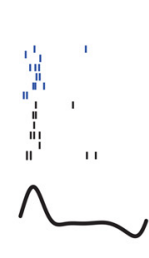

E

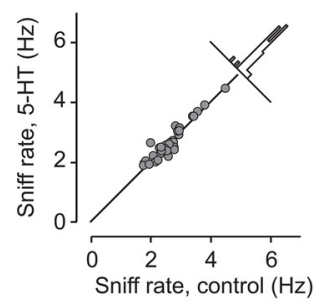

F

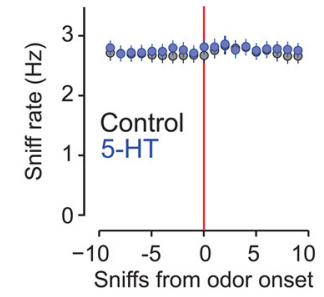

G

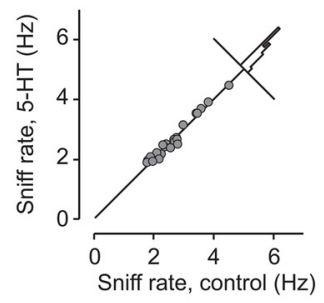

\section{I}

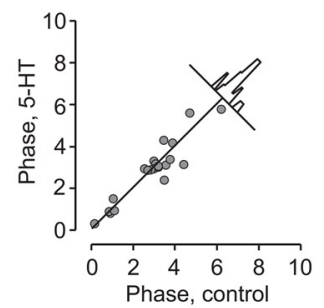

J

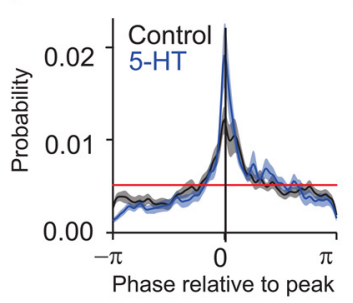

C

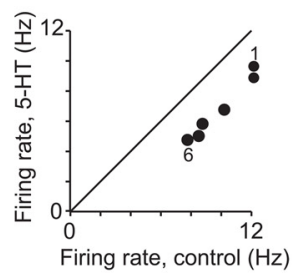

K

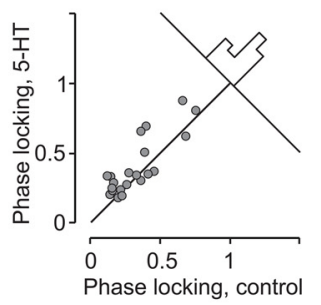

Figure 8. DRN photostimulation boosts respiratory coupling without changing its phase. $\boldsymbol{A}$, Left, Example raw data trials of neural activity and breathing for a stimulated (blue) and a nonstimulated (black) trial, respectively. Magenta bar indicates the odor stimulation, and blue line indicates photostimulation. Middle, Raster plot of the example data shown on the left; each row represents a single sniff sorted from the first sniff to the last (bottom to top, respectively). Blue ticks belong to photostimulated trials and black to control. The average respiration signal is shown below. Right, Sniff phase PSTH. Inset shows a polar plot of the average sniff phase of action potentials calculated from the PSTH (200 bins). $\boldsymbol{B}$, Sniff-averaged firing rate for all odor-neuron pairs belonging to inhibited, odor-responsive units ( $n=37$ ). C, Scatter plot comparing sniff-averaged firing rates in stimulated and control trials. Note the constant (subtractive) shift in firing across sniff cycles. $\boldsymbol{D}$, Instantaneous sniff rate ( $1 /$ snifflength) for all inhibited neurons aligned on photostimulation onset $(n=38)$. Shaded patches around the mean represent \pm SEM. $\boldsymbol{E}$, Scatter plot comparing sniff rates in the absence and presence of photostimulation $(n=38)$. Bar histogram shows the distribution of differences between photostimulated and control firing rates across the population. $\boldsymbol{F}$, Instantaneous sniff rate for all light-inhibited odor-responsive neurons aligned on odor onset $(n=25) . \mathbf{G}$, Scatter plot comparing sniff rates in the absence and presence of odor stimulation $(n=25)$. Bar histogram shows the distribution of differences between photostimulated and control firing rates across the population. $\boldsymbol{H}$, Sniff-averaged spike phase distribution during photostimulation trials relative to the peak phase of the corresponding control distribution for the population of sniff-locked inhibited neuron- odor pairs ( $n=21$ pairs). Data were aligned to the preferred phase for each neuron- odor pair and smoothed using a Gaussian filter with 0.08 radian SD. The horizontal red line marks chance. Shaded patches around the mean represent \pm SEM. I, Scatter plot comparing preferred phases in the absence and presence of photostimulation ( $n=21$ neuron- odor pairs). Bar histogram shows the distribution of differences between photostimulated and control firing rates across the population. J, Sniff-averaged spike phase distributions across the population of sniff-locked inhibited neuron- 0 dor pairs ( $n=21$ pairs) for control (black line) and photostimulation (blue line) conditions. Data were aligned to the preferred phase for each neuron- odor pair and each condition and smoothed using a Gaussian filter with 0.08 radian SD. The horizontal red line marks chance. Shaded patches around the mean represent \pm SEM. $\boldsymbol{K}$, Scatter plot showing the differences in phase coupling between photostimulated and control trials. Bar histogram shows the distribution of differences between photostimulated and control phase coupling across the population.

pocampal interneurons mediated by a mixed $5-\mathrm{HT}_{3}$ /glutamatergic mechanism, and this may lead to hyperpolarization of pyramidal neurons (Varga et al., 2009). Each of these effects could in principle contribute to our results. The selectivity of 5-HT photostimulation for spontaneous firing could reflect the known division of aPC inputs into a feedforward component from mitral/tufted cells in the $\mathrm{OB}$ via the LOT and a feedback component reflecting recurrent inputs from within the piriform cortex, as well as centrifugal inputs from other brain structures. In this model, release of 5-HT from DRN axons within the aPC would selectivity inhibit the recurrent synapses. If spontaneous activity were generated selectively by this recurrent input and odor-evoked selectively by LOT input, then selective inhibition of recurrent input by 5-HT could explain our results comprehensibly. Indeed, the neuromodulators acetylcholine and noradrenaline have been shown to differentially inhibit feedback versus LOT input (Hasselmo and Bower, 1992; Hasselmo et al., 1997).

However, despite the parsimony of this idea, for a number of reasons, we believe it is more likely that the simplicity of the effects is not purely the direct result of a singular underlying mechanism but instead reflects a well orchestrated convergence of mechanisms. As a first issue, it is thought that odor-evoked responses are dominated by recurrent rather than feedforward inputs (Poo and Isaacson, 2011). To selectively preserve odor-evoked spikes, 5 -HT would have to selectively suppress the recurrent circuitry responsible for spontaneous spikes while sparing the recurrent circuitry contributing to odorevoked activity. Interestingly, the somatostatin-expressing class of interneurons has been shown recently to produce a form of subtractive inhibition (Sturgill and Isaacson, 2015), resembling the effect of 5-HT.

A second complexity is that DRN 5-HT photostimulation is likely to affect circuits outside the aPC but that may indirectly affect spiking in the aPC. First, there are prominent 5 -HT projections to the $\mathrm{OB}$, in which $5-\mathrm{HT}$ can inhibit transmission in the olfactory glomeruli through a $5-\mathrm{HT}_{2 \mathrm{C}}$ receptor-mediated mechanism (Petzold et al., 2009). However, because other neuron types in the OB express 5-HT receptors (Tecott et al., 1993; McLean et al., 1995; Petzold et al., 2009), the overall effect of 
5-HT on OB output cannot readily be inferred from the effect at the glomerular level and remains to be tested. The DRN also projects to the locus ceruleus (Imai et al., 1986) and the basal forebrain (Semba et al., 1988) in which it excites noradrenergic (Szabo and Blier, 2001) and inhibits cholinergic (Bengtson et al., 2004), neurons respectively. Thus, the observed sparing of odorevoked activity suggests that various mechanisms within the aPC preserve odor-evoked responses, possibly even in the face of changing the activity in other brain areas. The contributions of these sources to the net effects on the aPC should also be considered.

\section{Endogenous control of DRN activity}

We have demonstrated that 5-HT can effect sensory processing on a rapid $(<200 \mathrm{~ms})$ timescale. Therefore, the role of $5-\mathrm{HT}$ in sensory processing will also depend on the timing of DRN 5-HT activation during behavior. Many DRN neurons respond rapidly to sensory stimuli (Montagne-Clavel et al., 1995; Waterhouse et al., 2004; Ranade and Mainen, 2009). One previous study examined the firing of DRN units during an odor discrimination task (Ranade and Mainen, 2009). The firing of many DRN neurons (of unrevealed neurochemical identity) was transiently suppressed shortly before and during odor sampling (Ranade and Mainen, 2009). This decrease would, interpreted in light of the present findings, yield an increase in aPC spontaneous activity. If this is the case for 5-HT neurons, this would be more consistent with spontaneous activity as reflecting stimulus priors, which would be most relevant during stimulus presentation, rather than noise, which would be most disruptive during stimulus presentation.

DRN neurons also respond to broad range of motor and reward-related events (Ranade and Mainen, 2009; Liu et al., 2014; Cohen et al., 2015; Zhou et al., 2015), and longer-term 5-HT effects are also to be expected. These will place sensory processing in the olfactory system under the control of higher-order behavioral states and conditions. The precise divisive effects on spontaneous activity reported here suggest that the modulatory effects of this system are suitable to regulate the relative gain of different information sources based on behavioral demands. Future experiments in behaving animals will be important to reveal how DRN 5-HT activity affects perception and perceptual expectations.

\section{References}

Araneda R, Andrade R (1991) 5-Hydroxytryptamine2 and 5-hydroxytryptamine $1 \mathrm{~A}$ receptors mediate opposing responses on membrane excitability in rat association cortex. Neuroscience 40:399-412. CrossRef Medline

Avesar D, Gulledge AT (2012) Selective serotonergic excitation of callosal projection neurons. Front Neural Circuits 6:12. CrossRef Medline

Basseville M, Nikiforov IV (1993) Detection of abrupt changes: theory and application. Englewood Cliffs, NJ: Prentice-Hall.

Bengtson CP, Lee DJ, Osborne PB (2004) Opposing electrophysiological actions of 5-HT on noncholinergic and cholinergic neurons in the rat ventral pallidum in vitro. J Neurophysiol 92:433-443. CrossRef Medline

Berkes P, Orbán G, Lengyel M, Fiser J (2011) Spontaneous cortical activity reveals hallmarks of an optimal internal model of the environment. Science 331:83-87. CrossRef Medline

Carandini M, Heeger DJ (2012) Normalization as a canonical neural computation. Nat Rev Neurosci 13:51-62. CrossRef Medline

Cohen JY, Amoroso MW, Uchida N (2015) Serotonergic neurons signal reward and punishment on multiple timescales. eLife 4:e06346. CrossRef Medline

Cools R, Roberts AC, Robbins TW (2008) Serotoninergic regulation of emotional and behavioural control processes. Trends Cogn Sci 12:31-40. CrossRef Medline

Datiche F, Luppi PH, Cattarelli M (1995) Serotonergic and nonserotonergic projections from the raphe nuclei to the piriform cortex in the rat: a cholera toxin B subunit (CTb) and 5-HT immunohistochemical study. Brain Res 671:27-37. CrossRef Medline
Davis M, Strachan DI, Kass E (1980) Excitatory and inhibitory effects of serotonin on sensorimotor reactivity measured with acoustic startle. Science 209:521-523. CrossRef Medline

Daw ND, Niv Y, Dayan P (2005) Uncertainty-based competition between prefrontal and dorsolateral striatal systems for behavioral control. Nat Neurosci 8:1704-1711. CrossRef Medline

Dayan P (2012) Twenty-five lessons from computational neuromodulation. Neuron 76:240-256. CrossRef Medline

Dayan P, Huys QJ (2009) Serotonin in affective control. Annu Rev Neurosci 32:95-126. CrossRef Medline

Deemyad T, Metzen MG, Pan Y, Chacron MJ (2013) Serotonin selectively enhances perception and sensory neural responses to stimuli generated by same-sex conspecifics. Proc Natl Acad Sci USA 110:19609-19614. CrossRef Medline

De Olmos J, Heimer L (1980) Double and triple labeling of neurons with fluorescent substances; the study of collateral pathways in the ascending raphe system. Neurosci Lett 19:7-12. CrossRef Medline

Dugué GP, Lörincz ML, Lottem E, Audero E, Matias S, Correia PA, Léna C, Mainen ZF (2014) Optogenetic recruitment of dorsal raphe serotonergic neurons acutely decreases mechanosensory responsivity in behaving mice. PLoS One 9:e105941. CrossRef Medline

Fiser J, Berkes P, Orbán G, Lengyel M (2010) Statistically optimal perception and learning: from behavior to neural representations. Trends Cogn Sci 14:119-130. CrossRef Medline

Fonseca MS, Murakami M, Mainen ZF (2015) Activation of dorsal raphe serotonergic neurons promotes waiting but is not reinforcing. Curr Biol 25:306-315. CrossRef Medline

Friston K (2010) Is the free-energy principle neurocentric? Nat Rev Neurosci 11:605. CrossRef Medline

Gautam SH, Verhagen JV (2012) Retronasal odor representations in the dorsal olfactory bulb of rats. J Neurosci 32:7949-7959. CrossRef Medline

Gellman RL, Aghajanian GK (1993) Pyramidal cells in piriform cortex receive a convergence of inputs from monoamine activated GABAergic interneurons. Brain Res 600:63-73. CrossRef Medline

Gellman RL, Aghajanian GK (1994) Serotonin2 receptor-mediated excitation of interneurons in piriform cortex: antagonism by atypical antipsychotic drugs. Neuroscience 58:515-525. CrossRef Medline

Haberly LB (1985) Neuronal circuitry in olfactory cortex: Anatomy and functional implications. Chem Senses 10:219-238. CrossRef

Haberly LB (1998) Olfactory cortex. In: The synaptic organization of the brain (Shepherd GM, ed), pp 377-416. New York: Oxford UP.

Haberly LB (2001) Parallel-distributed processing in olfactory cortex: new insights from morphological and physiological analysis of neuronal circuitry. Chem Senses 26:551-576. CrossRef Medline

Hasselmo ME, Bower JM (1992) Cholinergic suppression specific to intrinsic not afferent fiber synapses in rat piriform (olfactory) cortex. J Neurophysiol 67:1222-1229. Medline

Hasselmo ME, Linster C, Patil M, Ma D, Cekic M (1997) Noradrenergic suppression of synaptic transmission may influence cortical signal-tonoise ratio. J Neurophysiol 77:3326-3339. Medline

Imai H, Steindler DA, Kitai ST (1986) The organization of divergent axonal projections from the midbrain raphe nuclei in the rat. J Comp Neurol 243:363-380. CrossRef Medline

Isaacson JS (2010) Odor representations in mammalian cortical circuits. Curr Opin Neurobiol 20:328-331. CrossRef Medline

Jacobs BL, Azmitia EC (1992) Structure and function of the brain serotonin system. Physiol Rev 72:165-229. Medline

Kepecs A, Uchida N, Mainen ZF (2006) The sniff as a unit of olfactory processing. Chem Senses 31:167-179. CrossRef Medline

Kersten D, Mamassian P, Yuille A (2004) Object perception as Bayesian inference. Annu Rev Psychol 55:271-304. CrossRef Medline

Knill DC, Pouget A (2004) The Bayesian brain: the role of uncertainty in neural coding and computation. Trends Neurosci 27:712-719. CrossRef Medline

Litaudon P, Amat C, Bertrand B, Vigouroux M, Buonviso N (2003) Piriform cortex functional heterogeneity revealed by cellular responses to odours. Eur J Neurosci 17:2457-2461. CrossRef Medline

Liu S, Aungst JL, Puche AC, Shipley MT (2012) Serotonin modulates the population activity profile of olfactory bulb external tufted cells. J Neurophysiol 107:473-483. CrossRef Medline

Liu Z, Zhou J, Li Y, Hu F, Lu Y, Ma M, Feng Q, Zhang JE, Wang D, Zeng J, Bao J, Kim JY, Chen ZF, El Mestikawy S, Luo M (2014) Dorsal raphe neurons 
signal reward through 5-HT and glutamate. Neuron 81:1360-1374. CrossRef Medline

Marek GJ, Aghajanian GK (1994) Excitation of interneurons in piriform cortex by 5-hydroxytryptamine: blockade by MDL 100,907, a highly selective 5-HT2A receptor antagonist. Eur J Pharmacol 259:137-141. CrossRef Medline

McLean JH, Darby-King A, Paterno GD (1995) Localization of 5-HT2A receptor mRNA by in situ hybridization in the olfactory bulb of the postnatal rat. J Comp Neurol 353:371-378. CrossRef Medline

Montagne-Clavel J, Oliveras JL, Martin G (1995) Single-unit recordings at dorsal raphe nucleus in the awake-anesthetized rat: spontaneous activity and responses to cutaneous innocuous and noxious stimulations. Pain 60:303-310. CrossRef Medline

Petzold GC, Hagiwara A, Murthy VN (2009) Serotonergic modulation of odor input to the mammalian olfactory bulb. Nat Neurosci 12:784-791. CrossRef Medline

Poo C, Isaacson JS (2011) A major role for intracortical circuits in the strength and tuning of odor-evoked excitation in olfactory cortex. Neuron 72:41-48. CrossRef Medline

Ranade SP, Mainen ZF (2009) Transient firing of dorsal raphe neurons encodes diverse and specific sensory, motor, and reward events. J Neurophysiol 102:3026-3037. CrossRef Medline

Rao RP, Ballard DH (1999) Predictive coding in the visual cortex: a functional interpretation of some extra-classical receptive-field effects. Nat Neurosci 2:79-87. CrossRef Medline

Sara S (1985) The locus coeruleus and cognitive function: attempts to relate noradrenergic enhancement of signal/noise in the brain to behavior. Physiol Psychol 13:151-162. CrossRef

Semba K, Reiner PB, McGeer EG, Fibiger HC (1988) Brainstem afferents to the magnocellular basal forebrain studied by axonal transport, immunohistochemistry, and electrophysiology in the rat. J Comp Neurol 267: 433-453. CrossRef Medline

Servan-Schreiber D, Printz H, Cohen JD (1990) A network model of catecholamine effects: gain, signal-to-noise ratio, and behavior. Science 249: 892-895. CrossRef Medline

Shadlen MN, Newsome WT (1994) Noise, neural codes and cortical organization. Curr Opin Neurobiol 4:569-579. CrossRef Medline

Sheldon PW, Aghajanian GK (1991) Excitatory responses to serotonin (5-HT) in neurons of the rat piriform cortex: evidence for mediation by 5 -HT1C receptors in pyramidal cells and 5-HT2 receptors in interneurons. Synapse 9:208-218. CrossRef Medline
Soubrie P (1986) Reconciling the role of central serotonin neurons in human and animal behavior. Behav Brain Sci 9:319-335. CrossRef

Spors H, Wachowiak M, Cohen LB, Friedrich RW (2006) Temporal dynamics and latency patterns of receptor neuron input to the olfactory bulb. J Neurosci 26:1247-1259. CrossRef Medline

Sturgill JF, Isaacson JS (2015) Somatostatin cells regulate sensory response fidelity via subtractive inhibition in olfactory cortex. Nat Neurosci 18 : 531-535. CrossRef Medline

Summerfield C, de Lange FP (2014) Expectation in perceptual decision making: neural and computational mechanisms. Nat Rev Neurosci 15: 745-756. CrossRef Medline

Szabo ST, Blier P (2001) Functional and pharmacological characterization of the modulatory role of serotonin on the firing activity of locus coeruleus norepinephrine neurons. Brain Res 922:9-20. CrossRef Medline

Tecott LH, Maricq AV, Julius D (1993) Nervous system distribution of the serotonin 5-HT3 receptor mRNA. Proc Natl Acad Sci USA 90:1430-1434. CrossRef Medline

Varga V, Losonczy A, Zemelman BV, Borhegyi Z, Nyiri G, Domonkos A, Hangya B, Holderith N, Magee JC, Freund TF (2009) Fast synaptic subcortical control of hippocampal circuits. Science 326:449-453. CrossRef Medline

Waterhouse BD, Devilbiss D, Seiple S, Markowitz R (2004) Sensorimotorrelated discharge of simultaneously recorded, single neurons in the dorsal raphe nucleus of the awake, unrestrained rat. Brain Res 1000:183-191. CrossRef Medline

Wilson DA (1998) Habituation of odor responses in the rat anterior piriform cortex. J Neurophysiol 79:1425-1440. Medline

Winterer J, Stempel AV, Dugladze T, Földy C, Maziashvili N, Zivkovic AR, Priller J, Soltesz I, Gloveli T, Schmitz D (2011) Cell-type-specific modulation of feedback inhibition by serotonin in the hippocampus. J Neurosci 31:8464-8475. CrossRef Medline

Yu AJ, Dayan P (2002) Acetylcholine in cortical inference. Neural Netw 15:719-730. CrossRef Medline

Zhou J, Jia C, Feng Q, Bao J, Luo M (2015) Prospective coding of dorsal raphe reward signals by the orbitofrontal cortex. J Neurosci 35: 2717-2730. CrossRef Medline

Zhuang X, Masson J, Gingrich JA, Rayport S, Hen R (2005) Targeted gene expression in dopamine and serotonin neurons of the mouse brain. J Neurosci Methods 143:27-32. CrossRef Medline 